\title{
Frontières
}

\section{Ali Dizboni, Islam and War, Lewiston, The Edwin Mellen Press, 2011, 349 p.}

Jean-Jacques Lavoie

Volume 25, numéro 1, automne 2012

Le vieillissement et sa diversité

URI : https://id.erudit.org/iderudit/1018240ar

DOI : https://doi.org/10.7202/1018240ar

Aller au sommaire du numéro

Éditeur(s)

Université du Québec à Montréal

ISSN

1916-0976 (numérique)

Découvrir la revue

Citer ce compte rendu

Lavoie, J.-J. (2012). Compte rendu de [Ali Dizboni, Islam and War, Lewiston, The Edwin Mellen Press, 2011, 349 p.] Frontières, 25(1), 191-192.

https://doi.org/10.7202/1018240ar d'utilisation que vous pouvez consulter en ligne.

https://apropos.erudit.org/fr/usagers/politique-dutilisation/ 


\section{Ali Dizboni}

\section{Islam and War}

Lewiston, The Edwin Mellen Press, 2011, 349 p.

\section{Jean-Jacques Lavoie}

Le lien entre la guerre et la mort est évident, mais ce lien peut être éclairé de différentes manières. Dans le présent livre, Ali Dizboni, qui est professeur au département de science politique au Collège royal militaire du Canada, à Kingston, nous propose un éclairage à la fois religieux, juridique, historique et politique. Dans un premier chapitre, il nous convie d'abord à la découverte de diverses publications, afin de bien mettre en évidence les lacunes dans les études classiques et récentes sur la notion de Djihad. Le deuxième chapitre vise surtout à donner un éclairage de type historique. À l'aide des sources premières, rédigées en arabe, mais aussi en persan pour l'islam shi'ite, l'auteur analyse soigneusement le contexte historique de l'émergence du discours sur le Djihad. Cette enquête historique lui permet d'examiner non seulement I'expansion militaire de l'État musulman de Médine, mais aussi et surtout l'évolution du droit musulman et les diverses fonctions économiques de la guerre. Dans le troisième chapitre, I'objectif de l'auteur est d'analyser les raisons pour lesquelles la doctrine classique du Djihad demeure figée dans un discours révolu et fermé au changement. Pour atteindre son objectif, il présente d'abord de manière rigoureuse les critiques de divers penseurs musulmans (classiques, néoclassiques, modernistes, etc.) à l'égard du Djihad. Puis, il montre les faiblesses de leurs critiques, aussi bien du point de vue épistémologique (par exemple, la prétention à un savoir absolu) que méthodologique (par exemple, le caractère anhistorique et non empirique, voire anti-historique et anti-empirique de leurs discours). Après avoir examiné le contexte dans lequel est né le concept de Djihad et les discours classiques et contemporains sur le Djihad, Dizboni élargit la perspective et nous brosse un portrait de l'évolution technologique de la guerre, depuis le $15^{\mathrm{e}}$ siècle jusqu'au $20^{\mathrm{e}}$ siècle. Il entend ainsi 
montrer, avec de nombreux chiffres à l'appui, que les disproportions de plus en plus grandes entre les bénéfices et les coûts, aussi bien en vies humaines qu'en argent, font que la justification économique si importante dans la doctrine classique du Djihad devient caduque. Dans le dernier chapitre, I'auteur identifie quelques changements importants qui ont marqué, dans son ensemble, la culture contemporaine de la guerre. Parmi ces changements, il mentionne de nombreux discours nettement anti-guerre (par exemple, ceux des Quakers). Bien entendu, le fait que la Seconde guerre mondiale ait été nourrie par des idéologies nationalistes et un darwinisme social indique clairement que les changements n'ont pas toujours été positifs et favorables à la paix. Par ailleurs, Dizboni montre bien que, de tous les discours apparus après 1945, c'est celui du droit international, droit auquel adhèrent maints États-nations dans le monde musulman, qui assure maintenant, tant bien que mal, la paix dans le monde.

En somme, ce riche travail d'analyse comparée entre la culture de guerre au début de l'islam et celle du monde contemporain permet à l'auteur de déconstruire la notion de Djihad et de conclure que les discours djihadistes, encore promus de nos jours par certains groupes minoritaires, n'ont plus aucune légitimité. Certes, d'aucuns se demanderont peut-être si un aussi long détour était nécessaire pour arriver à cette conclusion. À mon avis, la réponse positive ne fait pas de doute: ce livre s'adresse à ceux et celles qui veulent aller au-delà des caricatures de l'islam et du Djihad et qui désirent construire la paix dans le monde tel qu'il est. Quant à ceux et celles qui se contentent de rêver la paix et qui ignorent naïvement que la nature et la diversité des causes des guerres interdisent toute forme d'optimisme quant à la possibilité de voir une paix mondiale s'établir de manière définitive, toute réflexion sur la guerre ne leur apparaîtra-telle pas toujours comme un inutile détour? 